\title{
Clinical tumour size and prognosis in lung cancer
}

\author{
Bronchogenic Carcinoma Cooperative Group of the Spanish Society of \\ Pneumology and Thoracic Surgery (GCCB-S)
}

\begin{abstract}
Clinical tumour size and prognosis in lung cancer. Bronchogenic Carcinoma Cooperative Group of the Spanish Society of Pneumology and Thoracic Surgery (GCCB-S). (C)ERS Journals Ltd 1999.

ABSTRACT: In the staging of lung cancer (LC), tumour size is a variable that can be used to separate primary tumour, regional nodes, metastasis (TNM), stages T1 and T2 $(<3$ or $>3 \mathrm{~cm})$. The objective of this study was to evaluate the prognostic value of tumour size before thoracotomy and to determine whether tumour size can be used to classify $L C$ as $T 3$.

This multi-institutional cooperative longitudinal prospective study in Spanish hospitals located throughout the country, with a broad range of activity levels, included all consecutive cases of LC treated surgically from October 1993 to September $1996(n=2,361)$.

Four prognostic groups, characterized by tumour size, were identified according to the Schoenfeld procedure: a) 0-2 cm $(\mathrm{n}=173)$; b) $2.1-4 \mathrm{~cm}(\mathrm{n}=542)$; c) $4.1-7 \mathrm{~cm}(\mathrm{n}=$ $413)$; and $d)>7 \mathrm{~cm}(\mathrm{n}=77)$. The 2 -yr survival rates by group were $\mathbf{a}=0.78(95 \%$ confidence interval (CI) 0.71-0.84); $b=0.67(95 \%$ CI 0.62-0.71); $c=0.58$ (95\% CI 0.53-0.63); $d=0.41(95 \%$ CI $0.29-0.52)$. The log-rank comparisons of the survival curves were significant for the four groups (a versus $b=0.0008$, b versus $c=0.003$, c versus $\mathrm{d}=0.016$ ).

The clinical tumour size of lung cancer defined four prognostic groups $(0-2 \mathrm{~cm}, 2.1-$ $4 \mathrm{~cm}, 4.1-7 \mathrm{~cm}$; and $>7 \mathrm{~cm})$. Lung cancer with a diameter $>7 \mathrm{~cm}$ had a prognosis similar to that of stage T3 or stage IIB.
\end{abstract}

Eur Respir J 1999; 14: 812-816.

\author{
Correspondence: A. López-Encuentra \\ Pneumology Service \\ Hospital Universitario 12 de Octubre \\ Ctra. de Andalucá, km 5,4 \\ E-28041 Madrid \\ Spain \\ Fax: 34913908358
}
Keywords: Cohort study
lung neoplasm
registry
staging
TNM classification
tumour size

Received: January 191999

Accepted after revision May 151999

This work was partly financed by FIS grant (97/0011), FEPAR-PENSA 1995 grant, and financial aid from the CastillaLeón government and Menarini Foundation.
In Spain, the incidence and mortality of lung cancer (LC) have increased in recent decades [1].

In the initial stages (stages I-II) of non-small-cell lung cancer (NSCLC), the therapy of choice is surgery if the patient can tolerate lung resection. However even in these stages, surgery is not a guaranteed cure. Only $63.5 \%$ of patients with stage I LC treated surgically survive $\geq 5$ yrs [2]. Moreover, the results obtained for the same prognostic groups vary widely from one series to another; for instance, reported 5-yr survival rates for primary tumour, regional nodes, metastasis (TNM) classification, T1N0M0 tumours range $68.5-83 \%$ [3].

These findings suggest the need for other factors, perhaps of a molecular type, to improve the accuracy of prognostic predictions and to establish the most suitable adjuvant therapies [4]. However, in spite of the initially promising results that have been obtained in initial LC with factors other than the TNM classification, subsequent studies have failed to confirm the reproducibility of these factors as prognostic markers [5]. In recent studies of resected NSCLC, certain molecular markers and tumour size have shown a similar prognostic value in multivariate analysis [6, 7]. In other studies of stage IIIA tumours with complete resection, univariate analysis shows that tumour size is not an independent prognostic factor for survival when using a cut-off value of $4 \mathrm{~cm}$, but variables such as angiogenesis are [8]. In patients with NSCLC undergoing surgery with intent to cure (stages I-IIIA), univariate analysis confirms the prognostic value of molecular factors, separately or associated, but not the prognostic value of the surgical-pathological tumour size classification [9]. One source of discrepancies in the prognostic value of molecular factors may be the inconsistency of measurements of the fundamental prognostic factors [3], which are included in the classification of anatomic extension (TNM classification stages) $[10,11]$.

Assuming that studies of multiple prognostic factors in LC are a necessary step toward improving our capability for predicting prognosis, each factor used to classify anatomic extension should be analysed independently. The most frequent category is T2, defined as a tumour $>3 \mathrm{~cm}$ in diameter (with no upper limit), with or without other circumstances (proximity to a main bronchus, visceral pleural invasion, atelectasis or pneumonitis involving less than a whole lung). The validation or correction, if necessary, of the data that sustain anatomic classifications is the first goal in the construction of multifactorial prognostic indexes [12]. As noted by a consensus group of the International Association for the Study of Lung Cancer (IASLC), the construction of prognostic scales in LC using data collected before 1980 may yield questionable results [12]. Therefore, the IASLC has appointed a staging group to consider, among other questions, "confirmation of the prognostic independence of size in T2 (3 $\mathrm{cm}$ versus $4 \mathrm{~cm}$ versus $5 \mathrm{~cm}$, etc) in cases of resectable NSCLC" [12]. 
The goal of this study was to evaluate the prognostic value of clinical tumour size. It was determined whether various cut-off values for tumour diameter, in the absence of either visceral pleural involvement or other anatomic factors justifying a higher T classification, or metastases to lymph nodes or at a distance, could be an independent prognostic factor for classifying tumours as higher tumour (T) (T3) or stage classification in the clinical phase before thoracotomy.

\section{Material and methods}

\section{Study subjects}

All the patients included in the study had lung cancer in initial stages and underwent thoracotomy with intent to cure in hospitals pertaining to the Bronchogenic Carcinoma Cooperative Group of the Spanish Society of Pneumology and Thoracic Surgery (GCCB-S) [13]. The population characteristics are described in table 1 . In summary, the authors prospectively included all patients treated surgically from October 1993 to September 1996 in hospitals participating in the GCCB-S who presented the clinical picture that defined the initial population (table 1) [13]. The annual cumulative number of cases was close to $50 \%$ of total cases occurring in Spain. The participating GCCB-S centres had a wide variety of activities, including a representative range of number of beds, teaching or research activities (university and nonuniversity hospitals), public and private ownership, and number of interventions per year (8-100 interventions were performed in participating centres for this disease). The sample was complete, as verified by the inclusion in the registry of all patients undergoing surgery, including incomplete resections and exploratory thoracotomy.

Table 2 shows the initial total number of patients and exclusions for each study year. Death due to operative mortality has been excluded. The final number of cases included in the study of prognostic factors was 1,859 .

For the study of clinical tumour size as a prognostic factor, the cases classified as T1 or T2 without involvement of the visceral pleura, regional lymph nodes (with classificatory certainty) (see Methods section), or metastases at a distance were considered. Within the T2 criteria, proximity to the main bronchus was not considered to be an exclusion factor in this study because of its low probability of modifying the prognosis [14]. Although a correct multivariate analysis of all the cases should control the prognostic value of tumour size using other T or nodal (N) factors, it was considered more appropriate to avoid contaminating the results with data from more advanced tumours. These

Table 1. - Population characteristics

Clinical situation index
Bronchogenic carcinoma
Initial stages
Thoracotomy
Sample attributes
Representativity
Completeness
Exclusion criteria
Operative mortality
Neoadjuvant treatment with surgery
Unknown evolution since surgery

Table 2. - Initial total number of patients and exclusions for each study year

\begin{tabular}{lrrrr}
\hline & $1993-94$ & $1994-95$ & $1995-96$ & Total \\
\hline Patients registered & 718 & 822 & 821 & 2361 \\
Surgical mortality & 51 & 62 & 75 & 188 \\
Induction treatment & 42 & 31 & 38 & 111 \\
Loss of follow-up & 13 & 94 & 96 & 203 \\
Final population & 610 & 634 & 611 & 1859 \\
\hline
\end{tabular}

conditions were met by 1,205 cases, which included incomplete resections and exploratory thoracotomies because these particular conditions were not known at the time of the "clinical phase" analysis before thoracotomy.

\section{Methods}

In accordance with the initial design, the period of case recruitment was short. The same criteria for the functional operability of patients and oncological operability of the tumour were used in all the GCCB-S hospitals [15].

Each variable recorded in the registry was accompanied by the diagnostic procedure used for its classification. When several procedures were used, the procedure with the best resolution was chosen. Depending on the characteristics of the tumour, clinical tumour size was established using a chest radiograph or computerized axial tomography (CAT); for instance, in vertical diameters, a radiograph may, in some patients, prove to be more reliable than CAT. For other characteristics, for example, the classification of clinical N2 involvement, CAT or mediastinoscopy was used and the procedure was recorded in the registry. The degree of certainty of the TNM-stages classification depends on the diagnostic methods used. According to some international organizations, postmortem study yields the maximum certainty factor and the clinical findings yield the minimum certainty factor [10].

The clinical classification of isolated involvement of the visceral pleura is considered certain only if it is verified by a validated procedure (thoracoscopy). The classification of clinical N0 requires, as a minimum, the absence of lymph node involvement of $>1 \mathrm{~cm}$ in diameter in areas 4,7 , and 10 in CAT or magnetic resonance imaging (MRI), or the presence of negative mediastinoscopy in these zones [16]. For the clinical N1 classification, cytohistological certainty is based on transbronchial fine needle aspiration biopsy (FNAB) or hilioscopy, and none of the patients in these series underwent these tests. To confirm the presence of clinical N2, cytohistological certainty obtained by transbronchial, transthoracic or transesophageal FNAB, by mediastinoscopy-mediastinotomy, or by thoracoscopy is required.

Surgical-pathological N0 is classified by radical mediastinal lymph node dissection or sampling of at least four lymph node areas (2 (only in right LC), 4, 7, and 10 on the same side as the tumour) [16]. For the purpose of classifying the presence or absence of mediastinal lymph node involvement, a randomized study has demonstrated that sampling has a value similar to that of radical mediastinal lymph node dissection [17].

Internal and external audits were made firstly to review the ratio between the number of patients undergoing surgery and the number of cases included in the registry (standard over 95\%) and secondly, to review the validity 
of the data recorded for each case (standard $>70 \%$ ), including the consistency of tumoural staging. The criterion for the validity of the survival data was established as the existence of a known follow-up for $\geq 85 \%$ of the cases registered in each hospital [18]. In the hospitals that did not meet all these conditions, the cases corresponding to the period of problems were excluded. Finally, correct data transmission by a single central office from the paper record to the computer database was verified.

These procedures were designed to control the following aspects: selection bias of surgical cases; registered cases out of the total number of surgical cases; sample size; type of hospital; prognostic migration due to the prolonged period of case recruitment; classification with low or deficient degrees of certainty; contamination by data from incomplete series or erroneous data, and loss of long-term follow-up.

\section{Analysis}

The Schoenfeld procedure [19] was used to identify intervals of tumour size related with specific survival outcomes. In this procedure, the continuous variable of tumour size was reclassified arbitrarily into intervals or unit segments (centimetres in this case) with suspected clinical significance. A series of consecutive and overlapping segments was generated and its correlation with survival was confirmed statistically using the Cox proportional risk procedure [20], which revealed the magnitude of the relative risk for each stratum.

The 2-yr and $3 \mathrm{yr}$ survival of the resulting prognostic groups was anaysed and 95\% confidence intervals (CI) were calculated using life tables (actuarial survival) and log-rank comparisons of survival curves. Statistical significance was adjusted using the Bonferroni correction for paired comparisons between strata [21].

\section{Results}

\section{Population characteristics}

The mean age of the studied population for the purpose of examining clinical tumour size in relation to prognosis was $63.4 \pm 11$ yrs (SD). The clinical tumour type was epidermoid in 526 patients (44\%), adenocarcinoma in 306 (25\%), large cell carcinoma in $185(15 \%)$, unclassified carcinoma (non-small cell) in $180(15 \%)$, and small-cell in 8 patients $(1 \%)$. Tumour size in small-cell lung cancer ranged $1.5-4 \mathrm{~cm}$. Ninety per cent of the patients were male. Exploratory thoracotomy was performed in 161 patients (13\%), lobectomy or bilobectomy in 744 patients $(62 \%)$, pneumoectomy in $270(22 \%)$, and segmentectomy, atypical resection, or a combination of procedures in the rest of the patients

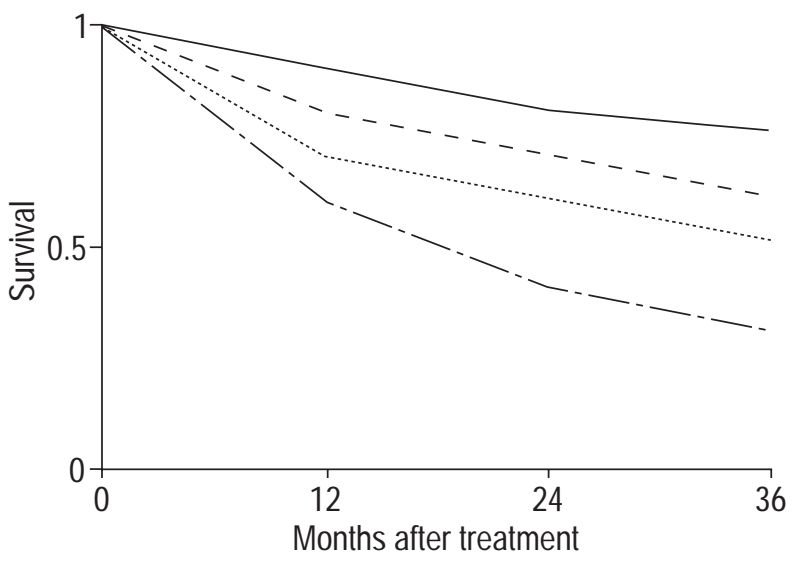

Fig. 1. - Cumulative probability of survival after treatment according to clinical tumour size; : $0-2 \mathrm{~cm}$ in diameter; - - : : 2.1-4 cm; - - - : 4.1-7 $\mathrm{cm} ;----:>7 \mathrm{~cm}$. Operative deaths are excluded.

\section{Clinical tumour size}

Mean tumour size before thoracotomy in the 1,205 classified cases was $4.24 \mathrm{~cm}$ (SD 1.97; median $2.4 \mathrm{~cm}$; range $0.5-15 \mathrm{~cm})$. In these 1,205 cases categorized as T1-T2 without visceral pleural involvement, N0 metastasis (M0), 12-month survival was 0.78 (95\% CI $0.76-0.80)$ and $24-$ month survival was 0.63 (95\% CI $0.60-0.66)$.

Using the Schoenfeld procedure [19], the Cox method [20] several cut-off values of tumour size were determined and selected on the basis of survival. Four tumour size intervals, generally $2-7 \mathrm{~cm}$ (table 3 ) were found. Each interval increased the risk of death by $50.8 \%$, with respect to the previous stratum; the different intervals showed increases of the same magnitude in the 2-yr and 3 -yr survival analysis. In this study, $3 \mathrm{~cm}$ was not a cutoff value for tumour size between prognostic categories.

The tumour-size groups had short-term survivals (1-2 yrs after surgery), showing statistically significant differences (table 3). At 3 yrs the statistical differences between the four groups were maintained $(\log -$ rank $=0.0002$, $0.009,0.002$, respectively) (fig. 1).

\section{Discussion}

The goal of the study was to analyse the prognostic value of clinical tumour size (as determined by radiology) of LC, independently of other factors, in initial clinical (c)T1-T2 stages without invasion of local structures (visceral pleura), involvement of regional lymph nodes, or distant metastases. Apart from being helpful in other areas, such information is perceived to be a valuable tool in quantifying the magnitude of benefit of the surgical

Table 3. - Prognostic groups and survival defined by clinical tumour size in relation to risk of death*

\begin{tabular}{lcccccc}
\hline Group & $\begin{array}{c}\text { Size } \\
\text { diameter in cm }\end{array}$ & $\mathrm{n}$ & $\begin{array}{c}\text { Risk ratio 2 yrs } \\
95 \% \text { CI }\end{array}$ & $\begin{array}{c}\text { S1 } \\
95 \% \text { CI }\end{array}$ & $\begin{array}{c}\text { S2 } \\
95 \% \text { CI }\end{array}$ & Log-rank \\
\hline a & $0-2$ & 173 & 1 & $0.90(0.86-0.95)$ & $0.78(0.71-0.84)$ & 0.0008 \\
b & $2.1-4$ & 542 & $1.9(1.3-2.7)$ & $0.82(0.79-0.86)$ & $0.67(0.62-0.71)$ & 0.003 \\
c & $4.1-7$ & 413 & $2.6(1.8-3.7)$ & $0.72(0.68-0.76)$ & $0.58(0.53-0.63)$ & 0.016 \\
d & $>7$ & 77 & $3.9(2.5-6.2)$ & $0.62(0.51-0.73)$ & $0.41(0.29-0.52)$ & \\
\hline
\end{tabular}

Data are presented as absolute number with $95 \%$ confidence intervals in parentheses. *: according to the procedure of SCHOENFELD [19]. The risk ratio was calculated according to the Cox method [20]; S1: cumulative probability of survival at $1 \mathrm{yr}$; S2: cumulative probability of survival at 2 yrs. 
treatment with regard to risk. The study comprised a large series of recent cases collected over a short time period. The study was multi-institutional and representative of cases of LC treated surgically in Spain, with an initial design conceived to control the usual bias in prognostic and/or therapeutic studies. These aspects of the methodology are particularly important in view of the variations in survival reported by different series for the same prognostic categories of LC [3].

The analysis found four groups of clinical tumour sizes related to risk of death: $0-2 \mathrm{~cm} ; 2.1-4 \mathrm{~cm} ; 4.1-7 \mathrm{~cm}$; and $>7 \mathrm{~cm}$. The $3 \mathrm{~cm}$ value was not confirmed as a prognostic separator in staging by the current study. The short-term survival (1-2 yrs) after surgery in the group of patients with tumours $>7 \mathrm{~cm}$ in diameter is similar to that of TNM anatomic classifications and/or stages superior to T2/IB (table 4). For LC $>7 \mathrm{~cm}$ in diameter, the 2 -yr probability of survival is closer to that of cT3N0M0 or cT2N1M0, or stage cIIB [22], than to the survival of the category in which it theoretically belongs, cT2N0M0 (2-yr survival probability: 0.54) [22].

When evaluating these results, the univariate nature of the study, which excluded other LC groups from analysis, should be emphasized. These other LC groups, might, in multivariate analysis, demonstrate the independent prognostic value of tumour size, even in the presence of more advanced tumour classification conditions.

The comparison of the present data with a recently published study of survival using the TNM-staging classification [22] is appropriate because its prognostic data was used for the elaboration of the new 1997 classification [11], (data is reported in clinical and/or surgicalpathological categories on a yearly basis for $5 \mathrm{yrs}$ ), and also because it includes small-cell LC in cT1-2N0M0 (3.8\% in their series [22]) and excludes cases of surgical mortality that occurred in the first 30 days after surgery. However, it is not clear if thoracotomy with incomplete resection and exploratory thoracotomy are included in the data relative to the clinical phase and the surgicalpathological classification.

Each prognostic category of the TNM classification (T1, $\mathrm{T} 2$, N2, etc) contains distinct internal components (tumour size, atelectasis, invasion of specific neighbouring structures). In theory, each component should be analysed independently so that, after a correct classification has been made, their prognostic value in relation to different survival times can be determined.

Of the components making up each prognostic category, the first factor evaluated by the GCCB-S was tumour size. This variable has a high level of classificatory certainty that is attainable with simple, universally available methods (chest radiograph or thoracic CAT); no prognostic migration is expected as a result of advances in diagnostic

Table 4. - Prognostic equivalence between some clinical tumour sizes and the new tumour classification (1997)

\begin{tabular}{lcrc}
\hline First author [Ref] & Category & $\mathrm{n}$ & $\begin{array}{c}\text { 2-yr } \\
\text { survival }\end{array}$ \\
\hline Present author & $\mathrm{T}>7 \mathrm{~cm}, \mathrm{~N} 0, \mathrm{M} 0$ & 77 & 0.41 \\
MounTAIN [22] & T3, N0, M0 & 107 & 0.37 \\
MounTAIN [22] & T2, N1, M0 & 250 & 0.42 \\
MounTAIN [22] & IIB & 357 & 0.41 \\
\hline
\end{tabular}

technology. The prognostic value of tumour size has been studied for many years [23-25]. In 1974, the first TNM classification was described after an evaluation of more than 300 curves and survival tables for 2,155 patients treated in the previous 4 yrs [26], which has conserved its basic structure until the present. One criterion that has not changed is the tumour size used to differentiate the T1 and T2 categories, which has a cut-off value of $3 \mathrm{~cm}$. In fact, T3, as described in 1974, has undergone more modifications as a result of the prognostic stratification of its internal variables. However, T2 has not changed substantially other than to incorporate visceral pleural involvement. In a recent publication of prognostic data, which largely sustains the new tumoural classification of anatomic extension of 1997 [22], 77,000 cases were evaluated, of which $>5,000$ cases were collected after 1975 and almost 4000 cases were evaluated before CAT was introduced in 1982 .

As shown in table 4, the prognostic significance of tumours $>7 \mathrm{~cm}$ is similar to that of TNM groups or more advanced clinical stages. Compared with other recent experiences $(2,382$ resected NSCLC), the probability of survival at 2 yrs calculated by the GCCB-S for tumours $>7 \mathrm{~cm}$ in diameter was similar to that of stage IIIA (T. Naruke, National Cancer Centre, Tokyo, Japan; personal communication, 1997). Some groups have recommended, in the light of survival data, that LC $>5 \mathrm{~cm}$ in diameter be classified as a higher category of $\mathrm{T} 2$ (stage IB) or by creating a new category, T2bN0M0, within stage II [24].

In recent literature, cases of LC treated by surgical resection in Spain show significant prognostic differences for small variations in tumour size: for example, between two groups of tumours $<3 \mathrm{~cm}(0-2 \mathrm{~cm}$ versus $2-3 \mathrm{~cm})$ found in a population of 154 T1N0M0 patients had significantly different 5 - and 10-yr prognoses after surgery [14].

In initial stages of LC in functionally inoperable patients who were treated by irradiation, different survival levels (considering only LC-specific mortality) have been detected for different tumour-size cut-off values. The 3-yr survival rate was $30 \%$ for tumours $>3 \mathrm{~cm}, 17 \%$ for $3-6 \mathrm{~cm}$, and $0 \%$ for tumours $>6 \mathrm{~cm}$ (only 9 cases) [27].

Prognostic results vary for initial lung cancer stages when the variable tumour size is controlled, even when restricted to T1-2N0M0 groups. This may be due to the presence of other variables contained within T1 or T2 [10], to biological-molecular factors [4], or to association with other diseases [28]. With regard to comorbidity, a large percentage of patients with initial stages of LC die from associated disease [27, 28].

This study has certain limitations, the first of which is the absence of internal validation. The study population is described herein, but not the validation population, which has not yet been evaluated because it was recruited in the final year (1996-1997). Another limitation is that the data correspond to a short follow-up period ( $2 \mathrm{yrs}$ ), although ideally the final analysis time in LC should be 10 yrs. However, values obtained at 1,2 and 3 yrs and the survival curves are fundamental for responsible decision-making by the physician and patient [29].

Given the current possibilities for obtaining homogeneous populations and using homogeneous study methods, and the current ease of information exchange, a process of convergence among databases throughout the world should be started and their compatibility studied. This would lead 
to larger and more representative sample sizes; which would probably improve prediction and prognostic accuracy. This measure is considered necessary and is defended as a major research challenge in lung cancer by the International Association for the Study of Lung Cancer [12], which proposes to "collect and review existing databases of cooperative groups and other institutions in order to validate clinical primary tumour, regional nodes, metastasis" in non-small-cell lung cancer.

Bronchogenic carcinoma cooperative group of the Spanish society of pneumology and thoracic surgery

Coordinators: J. Luis Duque (Hospital Universitario, Valladolid); A. López Encuentra (Hospital Universitario 12 de Octubre, Madrid); R. Rami Porta (Hospital Mutua de Terrassa, Barcelona). Local representatives: J. Astudillo (Hospital Germans Trias i Pujol, Barcelona); E. Canalś, J. Belda (Hospital Clinic, Barcelona); A. Cantó, A. Arnau (Hospital Clńico, Valencia); J. Casanova, M. Mariñan (Hospital de Cruces, Bilbao); J. Cerezal, F. Heras (Hospital Universitario, Valladolid); A. Fernández de Rota, R. Arrabal (Hospital Carlos Haya, Málaga); F. González Aragoneses, N. Moreno (Hospital Gregorio Marañón, Madrid); J. Freixinet, P. Rodrguez Suarez (Hospital Nuestra Señora del Pino, Las Palmas); N. Llobregat, J. Antonio Garrido (Hospital Universitario del Aire, Madrid); N. Mañes, J.M. Garcá Prim (Fundación Jiménez Dáz, Madrid); M. Mateu, E. Barbeta Sanchez (Hospital Mutua de Terrassa, Barcelona); J. Luis Martń de Nicolás, C. Marrón (Hospital Universitario 12 de Octubre, Madrid); N. Novoa (Complejo Hospitalario, Salamanca); J. Rodróuez, F.A. de Linera (Complejo Hospitalario, Oviedo); A. José Torres Garcá, A. Gómez (Hospital Universitario San Carlos, Madrid); J. José Rivas, M. de la Torre (Hospital Juan Canalejo, La Coruña); A. Sanchez-Palencia, F. Javier Ruiz Zafra (Hospital Virgen de las Nieves, Granada); A. Varela Ugarte, P. Gamez (Clńica Puerta de Hierro, Madrid); Y. Wah Pun (Hospital de la Princesa, Madrid). Data analysis: P. Ferrando, A. Goméz de la Cámara (Unidad de Epidemiologá Clíica, Hospital Universitario 12 de Octubre, Madrid).

\section{References}

1. Izarzugaza Lizarraga I. El cáncer de pulmón en España. Revisión epidemiológica. Arch Bronconeumol 1992; 28: 311-319.

2. Mountain CF. A new international staging system for lung cancer. Chest 1986; 89: Suppl. 4, 225-233.

3. Nesbitt JC, Putnam JB, Walsh GL, Roth JA, Mountain CF. Survival in early-stage non-small cell lung cancer. Ann Thorac Surg 1995; 60: 466-472.

4. Hermanek P, Gospodarowicz MK, Henson DE, Hutter RVP, Sobin LH. Prognostic factors in cancer, 1st Edn. Berlin, Springer-Verlag, 1995.

5. Pastorino U, Andreola S, Tagliabue E, et al. Immunocytochemical markers in stage I lung cancer: relevance to prognosis. J Clin Oncol 1997; 15: 2858-2865.

6. Fontanini G, Lucchi M, Vignati S, et al. Angiogenesis as a prognostic indicator of survival in non-small-cell lung carcinoma: a prospective study. J Natl Cancer Inst 1997; 89: 881-886.

7. Apolinario RM, Van-der-Valk P, de Jong JS, et al. Prognostic value of the expression of $\mathrm{p} 53, \mathrm{bc} 1-2$, and bax oncoproteins, and neovascularization in patients with radically resected non-small-cell lung cancer. J Clin Oncol 1997; 15: 2456-2466.

8. Angeletti CA, Lucchi M, Fontanini G, et al. Prognostic significance of tumoral angiogenesis in completely resec- ted late stage lung carcinoma (stage IIIA-N2). Cancer 1996; 78: 409-415.

9. Dosake-Akita $\mathrm{H}, \mathrm{Hu} \mathrm{SX}$, Fujimo $\mathrm{M}$, et al. Altered retinoblastoma protein expression in non-small cell lung cancer. Cancer 1997; 79: 1329-1337.

10. Sobin LH, Wittekind Ch. UICC International Union Against Cancer, TNM Classification of malignant tumors. Fifth edition. New York, Wiley-Liss, 1997.

11. American Thoracic Society/European Respiratory Society. Pretreatment evaluation of non-small-cell lung cancer. Am J Respir Crit Care Med 1997; 156: 320-332.

12. Ginsberg R, Cox J, Green M, et al. Staging Classification Committee Consensus report. Lung Cancer 1997; 17: Suppl. 1, 11-13.

13. Grupo Cooperativo de Carcinoma Broncogénico de SEPAR (GCCB-S). Cirugá del carcinoma broncogénico en España. Estudio descriptivo. Arch Bronconeumol 1995; 31: 303-309.

14. Padilla J, Calvo V, Peñalver JC, Sales G, Morcillo A. Surgical results and prognostic factors in early non-small cell lung cancer. Ann Thorac Surg 1997; 63: 324-326.

15. López Encuentra A and the Bronchogenic Carcinoma Cooperative Group of the Spanish Society of Pneumology and Thoracic Society (GCCB-S). Criteria of functional and oncological operability in surgery for lung cancer. A multicenter study. Lung Cancer 1998; 20: 161-168.

16. American Thoracic Society. Clinical staging primary lung cancer. Am Rev Respir Dis 1983; 127: 1-6.

17. Izbicki JR, Passlick B, Karg O, et al. Impact of radical systematic mediastinal lymphadenectomy on tumor staging in lung cancer. Ann Thorac Surg 1995; 59: 209-214.

18. Grupo Cooperativo de Carcinoma Broncogénico de SEPAR (GCCB-S). Control de calidad en un registro multiinstitucional de carcinoma broncogénico. Arch Bronconeumol 1996; 32: Suppl. 2, 70.

19. Schoenfeld DA. Analysis of categorical data: logistic model. In: Mike and Stanley KE, eds. Statistics in Medical Research. New York, Wiley, 1982; pp. 433-454.

20. Cox DR. Regression models and life table. J R Stat Soc 1972; 34: 187-220.

21. Hastings RP. Supplementary library user's guide. Cary, NC, USA, SAS Institute, 1986; 437-466.

22. Mountain CF. Revisions in the International System for staging lung cancer. Chest 1997; 111: 1710-1717.

23. Soorae AS, Abbey-Smith R. Tumor size as a prognostic factor after resection of lung carcinoma. Thorax 1977; 32: 19-25.

24. Watanabe Y, Shimizu J, Oda M, et al. Proposals regarding some deficiencies in the new international staging system for non-small cell lung cancer. Jpn J Clin Oncol 1991; 21: $160-168$.

25. Strauss GM. Prognostic markers in resectable non-small cell lung cancer. Hemat Oncol Clin North Am 1997; 11: 409-434.

26. Mountain CF, Carr DT, Anderson WAD. A system for the clinical staging of lung cancer. Am J Roentg Rad Ther Nucl Med 1974; 120: 130-138.

27. Sandler HM, Curran WJ, Turrisi III AT. The influence of tumor size and pre-treatment staging on outcome following radiation therapy alone for stage I non-small cell lung cancer. Int J Radiat Oncol Biol Phys 1990; 19: 9-13.

28. Pastorino U, Valente M, Bedini U, et al. Effect of chronic cardiopulmonary disease on survival after resection for stage Ia lung cancer. Thorax 1982; 37: 680-683.

29. Mazur DJ, Hickam DH. Five-year survival curves: How much data are enough for patient-physician decision making in general surgery? Eur J Surg 1996; 162: 101-104. 